\title{
O LUGAR EM SUA MULTIDIMENSIONALIDADE
}

\section{PLACE AND ITS MULTIDIMENTIONALITY}

\author{
Marcio Luis Fernandes ${ }^{1}$ \\ ${ }^{1}$ Universidade do Estado do Rio de Janeiro (UERJ), Rio de Janeiro, RJ, Brasil
}

Correspondência para: Marcio Luis Fernandes (mlf2501@hotmail.com)

doi: $10.12957 /$ geouerj.2016.13988

Recebido em: 9 dez. 2014 | Aceito em: 21 dez. 2015

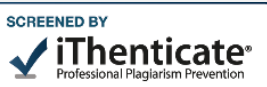

\section{RESUMO}

Em sua concepção clássica, o humanismo em geografia valoriza a existência em detrimento ao mundo material. O lugar vivido, no entanto, pressupõe o material e a imaterialidade; o concreto e o abstrato; o objetivo e o subjetivo. Como negligenciar a materialidade e os eventos espaciais que nos saltam aos olhos? Será que o mundo material que nos cerca, bem como as dinâmicas pelas quais estamos envoltos, não influenciam nossa existência? Uma das principais características do humanismo em geografia é sua natureza holística, vislumbrando a totalidade a fim de não perder a riqueza do todo. Não foi na brecha deixada pelo objetivismo exacerbado e pela consequente negligência aos valores subjetivos dos indivíduos e grupos sociais, atrelado aos paradigmas positivistas e neopositivistas, que o humanismo em geografia emergiu? Na minha concepção, o resultado do divórcio entre as dimensões objetivas e subjetivas da realidade, é a construção de uma geografia que não comunga com os anseios de uma ciência que nasceu com a ambição de descortinar o mundo em sua totalidade e diversidade. Nesse texto, meu objetivo é propor um exemplo de análise na linha intermediária, qual seja a integração cada vez maior entre as dimensões subjetivas e objetivas da realidade: o espacial e o existencial; o material e o imaterial etc.

Palavras-chave: Geografia humanística; Multidimensionalidade; Lugar; Materialidade; Imaterialidade.

\begin{abstract}
According to its classic conception in geography, humanism values existence over the material world. However, when place is analyzed as experience, it implies materiality and immateriality, concrete and abstract, objective and subjective. How to neglect materiality and the spatial events that take place before us? Does the material world that surround us as well as the dynamics by which we are surrounded - influence our existence? One of the main characteristics of humanism in geography is its holistic nature, which values the wholeness for the purpose of not losing the richness of the totality. Has not humanism in geography emerged from the loophole created by the exacerbated objectivism and by the consequent negligence to the subjective values of individuals and social groups? I personally believe that the detachment between objective and subjective dimensions of reality created the gap from which a geography that does not wish a science that was born with the ambition of unveiling the world in its totality and diversity emerged. In this text, I aim at proposing an example of analysis in the between line, integrating subjectivism and objectivism in the same reality: spatial and existential; material and immaterial ecc.
\end{abstract}

Keywords: Humanistic geografiphy. Multidimensionality. Lived place. Materiality.Imateriality.

\section{INTRODUÇÃO}

A orientação humanística surge como reação aos pressupostos positivistas e neopositivistas onde é nítida a separação entre sujeito e objeto. Além disso, na ciência positiva, os métodos quantitativos são priorizados, estando os adeptos destas abordagens, interessados unicamente na materialidade, ficando 
ausentes de seus estudos, a subjetividade, o simbolismo e as questões existenciais atreladas às experiências vividas pelos indivíduos e grupos sociais (MELLO, 1990; FERNANDES, 2014).

A partir do advento das perspectivas interpretativas, os diferentes significados inerentes ao universo vivido dos grupos sociais passam a representar o foco da investigação geográfica (CORREA E ROSENDAHL, 2012). Nesse contexto, os geógrafos passam a se debruçar sobre os laços que os indivíduos tecem entre si e seu universo vivido, bem como o porquê dos homens atribuírem significado e valores subjetivos aos seus lugares (CLAVAL, 2007).

Nas palavras de Gomes (2007), uma das principais características do humanismo em geografia é o seu caráter holístico, vislumbrando a totalidade a fim de não perder a riqueza do todo. Segundo Holzer (2008), a ideia de uma disciplina centrada no estudo da ação e da imaginação humana e na análise objetiva e subjetiva de seus produtos, que pretendiam constituir uma ciência de síntese que estivesse além dos parâmetros cartesianos e positivistas, nos remete aos anos 1920. Seguindo esta vertente, em 1947, Wrigth - por meio do conceito de geosofia - estabelece a base de um projeto de ciência que abarca as diferentes abordagens, bem como o objetivo e o subjetivo indistintamente (WRIGTH, 1947; LOWENTHAL, 1982; HOLZER, 1992).

Parafraseando Almeida (2010), em cada lugar convivem uma dimensão objetiva e outra subjetiva. Ambas, juntamente, constituem o vivido. A dimensão imaterial, no entanto, é aquela que dá o componente conotativo que acaba sendo, igualmente, parte inseparável da dimensão concreta (ALMEIDA, 2010).

No transcurso do processo de renovação da geografia, é comum, tanto o seu caráter de ruptura com os padrões anteriores (GOMES, 2007), quanto as tentativas de reconciliação de posições polarizadas (ALMEIDA, 2010). Conforme aponta Claval (2007), os geógrafos materialistas interessam-se pelas estruturas espaciais e os geógrafos humanistas pelas iniciativas e pelas ações individuais e coletivas. Para Claval, a integração cada vez maior entre as dimensões subjetivas e objetivas do lugar é um 
exemplo de análise na via intermediária entre duas abordagens: 0 espacial e 0 existencial; 0 urbanismo e o humanismo; o material e o imaterial etc.

Antonello (2010), buscando uma síntese entre as dimensões objetiva e subjetiva, aponta ser no lugar que se ancoram as experiências vividas. A autora assevera ainda que a geografia deve procurar a superação dos limites impostos pela divisão do trabalho científico, buscando trilhar um caminho que leve à pluralidade de focos de análise, a fim de compreender a complexa realidade que nos cerca (ANTONELLO, 2010).

Haesbaert (2005) é outro geógrafo que defende a indissociabilidade entre os aspectos objetivo e subjetivo. Em sua premissa de que a territorialidade é fruto do entrelaçamento entre as diferentes dimensões da realidade, o autor alerta que é justamente por fazer uma separação rígida entre território como dominação (material) e território como apropriação (simbólica) que muitos ignoram a complexidade e a riqueza da multiterritorialidade em que estamos envoltos (HAESBAERT, 2005).

Na concepção de Bastos (1998), o real não se constitui apenas do universo material, mas também dos significados oriundos da relação dos indivíduos com o seu mundo vivido. Para a pesquisadora, na apreensão do espaço geográfico há uma dimensão concreta (produção do espaço material) e uma dimensão simbólica (as representações). Essas duas dimensões da realidade interagem entre si em uma relação simbiótica (sujeito-objeto) e inseparável. Nesse sentido, espaços e lugares podem ser representados segundo um imaginário em que não se deve negar sua materialidade. Nesta trilha, não se justifica separar a subjetividade do pesquisador ao interpretar o lugar estudado, uma vez que o mesmo se apresenta de uma forma tal que o concreto e o abstrato são partes inseparáveis de uma mesma realidade. No dinâmico universo vivido onde o homem é o ator geográfico e o lugar o seu nicho de pertencimentos e memórias coletivas, há uma imbricação entre o material e o simbólico, entre o espacial e o existencial, entre o objetivo e o subjetivo (BASTOS, 1998).

Assim como os supramencionados pesquisadores, Cosgrove (2003) apregoa uma geografia em que as dimensões objetiva e subjetiva da realidade sejam consideradas. Para o citado geógrafo, os seres 
humanos promovem as transformações espaciais com sua realidade sensorial e material. Nesse sentido, toda atividade humana é material e simbólica ao mesmo tempo. Apesar de ser constituído simbolicamente, o mundo vivido é material e não deve negar sua objetividade (COSGROVE, 2003). As experiências vividas e as demais vivências subjetivas dos indivíduos e grupos sociais ocorrem em um contexto e não devem ser vistas como independentes da materialidade (CORREA A, 2003).

Segundo Geertz (2013), na antropologia - igualmente - há um debate interminável sobre se a cultura é subjetiva ou objetiva. Para o autor, a cultura deve ser entendida como um sistema entrelaçado de signos interpretáveis (símbolos), como um contexto onde as representações e o conteúdo substantivo encontram-se interligados. Em relação a esta complicação desnecessária, relacionada ao dualismo entre o concreto e o simbólico, Geertz salienta que tem procurado resistir ao subjetivismo desmedido e tentado manter a análise das formas simbólicas considerando ambas as dimensões da realidade (GEERTZ, 2013).

Afinado com os pesquisadores citados nesta seção (CORRÊA, 2003; COSGROVE, 2003; BASTOS, 1998; HAESBAERT, 2005; ANTONELLO, 2010; ALMEIDA, 2010; CLAVAL, 2007; WRIGTH, 1947; LOWENTHAL, 1982; GEERTZ, 2013) creio ser possível uma "abordagem sintética" nos estudos geográficos, onde - de igual modo - as diferentes dimensões do universo vivido sejam consideradas. Não foi na brecha deixada pelo objetivismo exacerbado e pela consequente negligência aos valores subjetivos dos indivíduos e grupos sociais, atrelado aos paradigmas positivistas e neopositivistas, que o humanismo em geografia emergiu?

Na minha concepção, o resultado do divórcio entre as dimensões objetivas e subjetivas advém da construção de uma geografia que não comunga com os anseios de uma ciência que nasceu com a ambição de descortinar o mundo em sua totalidade e diversidade (SILVA, 1988; CLAVAL, 2007; MARANDOLA JR, 2012).

As breves elucubrações partilhadas neste texto não têm a pretensão de serem rigorosas, exaustivas ou inovadoras. Isto seria difícil, mesmo porque intelectuais, inclusive geógrafos, vem se debruçando sobre 
a necessidade de abordagens que contemplam as múltiplas dimensões do vivido, quais sejam os aspectos objetivos e subjetivos que compreendem a ação humana sobre a face da Terra (o espacial e o simbólico/existencial). Ao trazer esse esboço teórico, meu objetivo é consubstanciar pesquisas que consistem na abordagem da complexidade sobre a qual os diferentes universos vividos encontram-se envoltos, sendo estes lugares compostos de múltiplas dimensões. Nos tópicos seguintes, nos debruçaremos sobre alguns conceitos e temas que podem embasar teoricamente pesquisas que privilegiem o lugar em sua multidimensionalidade.

\section{SÍMBOLOS, SIGNIFICADOS E REPRESENTAÇÕES}

Símbolo tem o poder de sugerir um todo, transcende sua condição como tal e como parte integrante se confunde com o lugar no qual se encontra. Neste particular, a carga simbólica de um templo ou de um estádio pode ser bem mais ampla, expressiva que a sua destinação original. Na verdade, a cruz simboliza a cristandade, a coroa a monarquia (TUAN, 2012) assim como o portal de Brandemburgo representa um dos símbolos máximos da nação alemã (FREITAS, 1999). O simbolismo, entendido como emblema ou interpretação do significado de determinado elemento simbólico (símbolo), manifesta-se nas últimas décadas como um conceito sumamente importante para as pesquisas humanísticas e culturais - estudos estes relacionados à compreensão da dimensão subjetiva do lugar (MELLO, 2000, 2003; TUAN, 2012). Segundo Cosgrove (2004):

\footnotetext{
Todas as paisagens possuem significados simbólicos porque são o produto da apropriação e transformação do meio ambiente pelo homem. O simbolismo é mais facilmente apreendido nas paisagens mais elaboradas - a cidade, o parque e o jardim - e através da representação da paisagem na pintura, poesia e outras artes. Mas pode ser lida nas paisagens rurais e mesmo nas mais aparentemente não humanizadas paisagens do meio ambiente natural. Estas últimas são, frequentemente, símbolos poderosos em si mesmos (COSGROVE, 2004, p.108).
}

Para compreender as expressões impressas por uma cultura em sua paisagem, necessitamos de um conhecimento da linguagem empregada: os símbolos e seu significado nessa cultura. Apesar da ligação ser muito tênue entre o símbolo e o que ele representa, no entendimento de Cosgrove, todas as paisagens são simbólicas. Ao salientar que os cenários humanos são carregados de simbolismo, o autor focaliza a natureza e a paisagem natural como símbolos poderosos em si mesmos, partindo do 
pressuposto de que qualquer intervenção humana na natureza envolve sua transformação em cultura. Apesar dessa transformação não estar sempre visível, especialmente para um estranho, o objeto natural torna-se objeto cultural quando lhe é atribuído um significado simbólico (COSGROVE, 2004). Observemos agora as palavras de Tuan (2012):

\footnotetext{
Dos múltiplos e variados motivos para mudar-se para o subúrbio, a busca de um meio ambiente saudável e de um estilo de vida informal estão entre os mais antigos. Temos repetidamente observado como o sentimento pela natureza e vida rural é encorajado pelas pressões da vida urbana. $\mathrm{O}$ meio ambiente da cidade é ao mesmo tempo sedutor e irritante, bonito e desagradável. Os ricos sempre puderam escapar disso saindo para descansar em suas casas de campo. No mundo ocidental o sentimento pela natureza culminou com o movimento romântico dos séculos XVII e XIX (...). A cidade simbolizava corrupção (...). O campo simbolizava a vida: a vida revelada nos frutos da terra, nas coisas verdes que crescem, na água pura e no ar limpo, na saudável família humana (TUAN, 2012, p. 324-325).
}

A simbologia não se restringe aos centros de bem querência, afetividade, despojamento ou experiência, pois espaços vastos, estranhos e distantes configuram-se como símbolos de rejeição (MELLO, 2003; TUAN, 2012). Entendendo o simbolismo como o marco de uma ideia - tanto negativa quanto positiva - de um determinado elemento simbólico, Tuan (2012) propõe um contraponto entre a cidade e o campo, sugerindo que a partir da revolução industrial, a cidade - aos poucos - deixa de simbolizar um ideal de vida, cedendo ao campo essa condição, por meio de um retorno ao sentimento pela natureza. Segundo Tuan, ao adquirir alguns dos valores do campo, o subúrbio - entendido como fronteira da expansão metropolitana - passa a representar um ideal, pois sugere um estilo de vida perfeito, no qual se combina o melhor da vida rural e urbana sem os seus defeitos (TUAN, 2012). Nesse sentido, seja para o contexto americano acima ou no âmbito dos subúrbios brasileiros e carioca, as periferias metropolitanas passam a representar para seus residentes um símbolo de bem querência (CORREAA, 2000; FERNANDES, 2006; SOUZA, 2005).

Lugares e símbolos adquirem profundo significado através dos laços emocionais tecidos ao longo dos anos. O próprio lugar constitui um símbolo de afetividade, bem querência, satisfação, felicidade e congraçamento, por um lado, mas, igualmente, palco de lutas e da lida do dia-a-dia. O caráter simbólico dos lugares estabelece conexões decodificando e traduzindo o seu passado e o conectando ao presente (MELLO, 1990; 2003). 
Ainda no tocante ao universo simbólico, consideremos as lucubrações da geógrafa Doreen Massey (2008):

E, assim, existe "lugar". No contexto de um mundo que é, certamente, cada vez mais interconectado, a noção de lugar (geralmente citado como "lugar local") adquiriu uma ressonância totêmica. Seu valor simbólico é, incessantemente, mobilizado em argumentos políticos. Para alguns, é a esfera do cotidiano, de práticas reais e valorizadas, a fonte geográfica de significado, vital como ponto de apoio, enquanto "o global" tece suas teias, cada vez mais poderosas e alienantes. Para outros, "um refúgio no lugar" representa a proteção de pontes levadiças e a construção de muralhas contra as novas invasões. Lugar, através dessa leitura, é o local da negação.

Em uma tentativa de traduzir o valor simbólico do lugar, Doreen Massey (2008, p.24-25) discorre sobre sua ampla gama de significados. Em sua perspectiva, o lugar simboliza - dentre outras coisas a esfera do cotidiano, a fonte geográfica de significado, vital ponto de apoio, além de representar refúgio e proteção contra as poderosas e alienantes teias do global. Defendendo um novo estímulo da espacialidade, a autora aponta a natureza e a paisagem natural como fundamentos simbólicos para 0 reconhecimento do lugar (MASSEY, 2008).

Adentrando neste universo de significados e valores, Joel Bonnemaison (2002, p.109-111) sublinha:

Um geossímbolo pode ser definido como um lugar, um itinerário, uma extensão que, por razões religiosas, políticas ou culturais, aos olhos de certas pessoas e grupos étnicos assume uma dimensão simbólica que os fortalece em sua identidade (...). Os símbolos ganham maior força e realce quando se encarnam em lugares. O espaço cultural é um espaço geossimbólico, carregado de afetividade e significações.

O geossímbolo - conceito trabalhado por Joel Bonnemaison (2002, p.109-111) - pode ser compreendido como um lugar-símbolo, carregado de afetividade e significações. Dentre as premissas defendidas pelos geógrafos do horizonte humanístico estão às relacionadas ao conteúdo simbólico dos lugares (COSTA, 2008) e ao mosaico de símbolos que residem no mesmo (MELLO, 2003, 2008). Nesse sentido:

O caráter simbólico dos lugares revela-se ao ser humano como algo que precede a linguagem e a razão discursiva, apresentando assim determinados aspectos do real, enfatizando as relações entre o simbólico e o lugar. Estas relações são mediatizadas pelos símbolos que podem ser uma 
realidade material e que se une a uma ideia, um valor, um sentimento. Entendemos, portanto, que as mediações simbólicas permeiam as atitudes pessoais em relação aos lugares (COSTA, 2008, p 149).

Para Costa (2008), certos elementos de ordem natural ou cultural, quando associados às relações cotidianas dos indivíduos ou grupos sociais, podem definir um conjunto de símbolos que expressam a memória do lugar. Nestas circunstâncias, as relações cotidianas e o consequente entendimento acerca dos lugares e de seus símbolos, podem fazer com que um espaço torne-se lugar, uma vez recortado afetivamente. "Nesse contexto, o lugar passa a ter seu interesse ampliado como referência da identidade e ao mesmo tempo adquire um valor simbólico" (COSTA, 2008, p. 155).

Considerando o universo simbólico dos lugares, conciliar, entender e decodificar seus símbolos pretéritos e hodiernos são tarefas a serem empreendidas pelos geógrafos que se debruçam sobre abordagens interpretativas.

\section{ESPACIALIDADES E TEMPORALIDADES}

Diante de um dado da realidade ou de uma informação sobre um acontecimento qualquer, duas perguntas são inevitáveis: quando ocorreu? Em que lugar? Esses questionamentos se devem ao fato de todo evento incidir sobre espacialidades determinadas e em temporalidades específicas (SANTOS, 2002). Pensar o lugar como compósito de espacialidades e temporalidades remete ao reconhecimento de sua dinâmica gerando e envolvendo formas, funções, conteúdos (ABREU, 2003) e significados (TUAN, 2013) inseridos em múltiplos níveis de investigação.

Durante um longo período, a geografia privilegiou a análise espacial sem conferir a devida atenção ao tempo (SALGUEIRO, 2003). Hodiernamente, no entanto, há de se valorizar as dimensões espacial e temporal (ABREU, 2003). As categorias espacialidade e temporalidade nos conduz, obviamente, a indagações sobre o espaço e o tempo (GEIGER, 2003). Todavia, a espacialidade ultrapassa a rigidez associada ao espaço como mero palco dos acontecimentos, representando uma vantagem na abordagem da espacialização de um fenômeno dinâmico como a urbanização, por exemplo. De modo semelhante, 
podemos falar de temporalidade referindo-nos aos distintos períodos (SALGUEIRO, 2003; FERNANDES, 2010). Nas abordagens geográficas não basta desvendar as múltiplas dimensões da espacialidade contemporânea. Faz-se necessário investigar - igualmente - as temporalidades pretéritas responsáveis pelas heranças já configuradas. Este é o caminho que o geógrafo deve trilhar, se almeja uma geografia genuinamente comprometida com a espacialidade (ABREU, 1997).

Espaço e tempo são categorias básicas da existência humana (HARVEY, 1992), uma vez que os mesmos coadunam diferentes temporalidades. Nas abordagens, torna-se indispensável introduzir temporalidade no espacial. Nessa leitura, espaço e tempo não são redutíveis um ao outro. São termos distintos, porém complementares (MASSEY, 2008).

As ações da natureza e do ser humano estão inscritas no espaço (espacialidade) e no tempo (temporalidade). Os fenômenos derivados das influências de ordem natural, social e existencial espraiam-se, localizam-se nos espaços e lugares por meio de seus limites e dimensões. Por meio dessas ações no espaço e no tempo, surgem os diferentes lugares. A espacialidade, bem como a temporalidade, emergem a partir da diferenciação da ação da natureza e do ser humano sobre a superfície terrestre

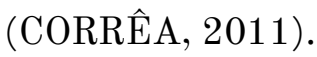

Nas palavras de Cosgrove (2004, p.110) "acima de tudo, é essencial uma sensibilidade histórica e contextual por parte do geógrafo. Devemos resistir à tentação de deslocar a paisagem de seu contexto de tempo e espaço".

As dimensões espacial e temporal do vivido sempre estiveram no âmago da perspectiva humanística em geografia. Tanto Lowenthal (1982) quanto Tuan $(2011 ; 2013)$ - pesquisadores apontados por Holzer (1992, p. 489) como "os pais incontestáveis da geografia humanística" - privilegiaram as citadas categorias nos estudos que fundamentaram a aludida corrente do pensamento geográfico. No parecer de Lowenthal (1982), o tempo exerce uma forte influência sobre nossas perspectivas individuais em relação aos nossos universos particulares. Para o citado pensador, "cada mundo particular teve uma carreira no tempo, uma história própria"(p.138), nesta direção, "toda história 
pessoal resulta de um meio ambiente particular" (p.139). A relação que nutrimos para com nosso universo vivido é construída a partir de nossa experiência vivida, e isso demanda tempo. Lowenthal conclui sua elaboração mental salientando que "todos os tipos de experiências (...), vêm juntos compor o nosso quadro individual da realidade" (p.141). No transcurso do tempo, "como artistas", podemos criar e/ou organizar espaços e lugares (LOWENTHAL, 1982, p.141).

Tuan (2011; 2013), igualmente, delega indiscutível relevância às dimensões espacial e temporal, elevando-as ao patamar de "arcabouço" do humanismo em geografia (TUAN, 2011, p.8). Em sua concepção, Tuan salienta que, "na imaginação é fácil tratar espaço" e "tempo separadamente". "Na experiência vivida", entretanto, "eles estão indissoluvelmente ligados" (TUAN, 2011, p.8). "O movimento exige tempo e ocorre no espaço" (p. 15). "Quanto mais tempo permanecemos em uma localidade melhor a conhecemos e mais profundamente significativa se tornará para nós" (p. 17). Para Tuan (2011, p. 18), espaço e tempo "são categorias sobrepostas da experiência humana. Se não forem consideradas em conjunto, o mundo dos geógrafos conservará um ar de irrealidade, abstraindo-se da vida como é vivida".

O tempo está implícito em todos os espaços e lugares. Todos nós temos um sentido de espaço e de tempo. "a facilidade com que confundimos as categorias espacial e temporal é evidente na linguagem". "Frequentemente o comprimento é dado em unidades de tempo" e "a passagem do tempo" é descrita como comprimento. "o tempo ainda é volume": os grandes momentos da vida (TUAN, 2013, p.147). "O espaço é histórico". Nesse sentido, "espaço e tempo sempre estiveram estruturados de acordo com os sentimentos e necessidades humanas individuais" (TUAN, 2013, p. 152-153). "O espaço tem significado temporal", tanto "nas reflexões do poeta", quanto "ao nível das experiências pessoais do dia a dia" (TUAN, 2013, p. 156). "O espaço e o tempo coexistem, entremesclam-se e cada um deles é definido de acordo com a experiência pessoal" (TUAN, 2013, p.161). "Tudo o que somos devemos ao passado. 0 presente também tem valor, é nossa realidade experiencial” (TUAN, 2013, p.239).

Em suas reflexões em busca de uma geografia que não se limita aos rigores científicos e acadêmicos, Wright (1947) indica a necessidade de que os geógrafos se ocupem tanto com os estudos da 
espacialidade quanto da geograficidade. Esta última, entendida como envolvimento profundo dos indivíduos e grupos sociais com o seu universo vivido, sendo esta a espacialidade íntima de cada ser humano. Nesta senda, tanto a espacialidade (características e dinâmicas dos lugares) quanto a geograficidade (experiências, vivências, significados e simbolismos) estão ligados à nossa existência. Por esse motivo, vale repetir, não se deve negligenciar a ambivalência e complementaridade desses dados essenciais da realidade (WRIGHT, 1947; DARDEL, 2011).

\section{POLIVOCALIDADE: AS MÚLTIPLAS INTERPRETAÇÕES DO UNIVERSO VIVIDO}

Não há como ignorar os laços sutis e complexos que unem o ser humano ao seu lugar. O simbólico e as demais conotações subjetivas estão presentes na prática de interpretar e analisar os espaços e lugares em seus significados. O ser humano é um geógrafo informal (LOWENTHAL, 1982) e o lugar o seu mundo vivido no qual as relações se mesclam em um emaranhado de laços, vivências e embates, onde estão presentes os sentimentos pessoais, as memórias coletivas e os símbolos. A partir desse ponto de vista, podemos entender o lugar como um reservatório de símbolos a ser interpretado, tanto por indivíduos comuns como, consequentemente, por geógrafos. O lugar, como abrigo humanizado, permite - com isso - múltiplas leituras concernentes a diferentes manifestações que expressam tantas interpretações quantas forem os significados subjetivos e intersubjetivos.

Os lugares dos seres humanos são compostos de várias camadas de significados. Estes múltiplos patamares fazem do universo vivido um lugar simbólico exposto à interpretação. Por esse prisma, a "geografia está em toda parte" (COSGROVE, 2004, p. 96) e cada indivíduo, por pensar e buscar entender seu mundo vivido torna-se um geógrafo informal (COSGROVE, 2004; LOWENTHAL, 1982), apto a interpretar seu universo particular.

Na concepção de Lowenthal (1982, p. 105) "qualquer pessoa que examine o mundo ao redor de si é, de algum modo, um geógrafo". Para o citado pensador, os especialistas deste saber precisam considerar que há outras pessoas decodificando o mundo sob diferentes olhares e que a visão do universo vivido não deve ser obtida apenas sob uma perspectiva. Cada concepção do mundo é única não havendo 
possibilidade de interpretações distintas (LOWENTHAL, 1982; CORRÊA, 2007). Neste ritmo, um dos motivos para que tais diferenciações acerca do vivido sejam únicas, diz respeito ao fato de toda informação ser inspirada e editada pelo sentimento dos indivíduos por seu lugar (LOWENTHAL, 1982).

Segundo Geertz (2013), o homem está amarrado a teias de significados por ele tecidas. A fim de decodificá-los, as leis científicas devem ceder lugar a filosofias interpretativas que deem conta de traduzir a gama de expressões inerente a toda atividade humana, ao mesmo tempo, material e simbólica (COSGROVE, 2003; GEERTZ, 2013).

Baseado em Hall (1997), Corrêa (2007, p.5) assevera que "os símbolos são abertos a diferentes interpretações, calcadas cada uma na experiência, valores, crenças, mitos e utopias do grupo social que o interpreta". Os significados atrelados aos símbolos variam de pessoa para pessoa. Essa condição promove a polivocalidade, isto é, as diversas interpretações a respeito do mesmo símbolo. A polivocalidade torna-se uma espécie de antídoto a um significado imposto, único ou unilateral (CORRÊEA, 2007).

A revelação sobre a ocorrência de múltiplas camadas de significado atrelada às relações humanas (GEERTZ, 2013), bem como no que concerne à sua sobreposição, por muito tempo foi negligenciada (PANOFSKY, 2004), apontando para uma necessidade premente: abordagens que privilegiem o elemento humano em sua multiplicidade, uma vez que o lugar é multidimensional.

\section{O LUGAR EM SUA MULTIDIMENSIONALIDADE}

Segundo Relph (2012), o lugar faz parte da preocupação dos filósofos desde a antiguidade clássica. Platão considerava-o como "o alimento do ser, enquanto outros o aproximavam de um sentido geográfico como o contexto em que os seres estão reunidos juntos" (RELPH, 2012, p. 18). A partir do século XVII, no entanto, a concepção cartesiana de espaço, como dimensão mensurável, excluiu o lugar da filosofia e das ciências. Somente no século XX, filósofos fenomenologistas - "especialmente 
Husserl, Heidegger, Merleau-Ponty" (RELPH, 2012, p. 18) - identificaram as profundas inadequações da lógica cartesiana. Na concepção desses pensadores, o positivismo promove a incisão da filosofia, ao deixar de fora os sentimentos, emoções, experiências dos seres humanos. A ciência positiva, ao reduzir espaços e lugares a uma única dimensão (material), promovia uma geografia deficiente (RELPH, 2012).

A supracitada indiferença à dimensão subjetiva da existência humana é, segundo Relph (2012), uma das possíveis motivações para o recente interesse pelo lugar. No entanto, o citado geógrafo não deixa de salientar que o conceito em questão possui múltiplas dimensões. Para Relph, além de reunir as qualidades, experiências e significados de nossa vivência, o lugar possui outros aspectos subjetivos (espírito, sentido, enraizamento, interioridade...) e também objetivos (localização, fisionomia, construções...). A essência do lugar pressupõe a observância de sua multidimensionalidade (RELPH, 2012).

Em seu debate sobre as dimensões significativas do lugar, Lívia de Oliveira (2012, p.12) aponta que "todo lugar adquire identidade mediante suas diversas dimensões espaciais: localização, direção, orientação, relação, território, espacialidade e outras". No texto em questão, a professora Oliveira busca uma junção entre as dimensões física, experiencial e simbólica a fim de sustentar as diferentes esferas ou camadas de significados "que se coadunam para a constituição do lugar" (MARANDOLA JR, 2012, p. 15).

Em suas laboriosas reflexões sobre lugar e sujeito, Berdoulay e Entrikin (2012) concordam que o sentimento intenso de pertencimento, que cria uma fusão entre o indivíduo e seu mundo vivido, pode ser promovido por elementos mensuráveis ou por relações existenciais efêmeras que compõem nossa vida cotidiana. Para os pensadores mencionados, ao promover modificações em seu lugar, os seres humanos transformam a Terra em seu mundo. Essas mudanças, por sua vez, afetam, igualmente, os indivíduos e grupos sociais em sua vida de relações. Nesse sentido, o sujeito (ser humano) e o lugar (realidade objetiva e subjetiva) são, cada um, constitutivos do outro (BERDOULAY E ENTRIKIN, 2012). 
O lugar - universo vivido, por excelência - vai além da objetividade geográfica que ignora as sutilezas responsáveis por seus aspectos valorativos (GALLAIS, 2002; FERNANDES, 2010). O vivido carrega consigo, igualmente, uma dimensão mais rica em aspectos subjetivos e existenciais. Trata-se de uma esfera de reconhecimento e familiaridade pertinente à vida cotidiana, onde sua significação aprofunda seu papel (geo)simbólico (BONNEMAISON, 2002).

Nas palavras de Dardel (2011), a geografia, obra do homem, exibe um espaço construído e possui significado. Estas construções exaltam o homem entrelaçando seus costumes, hábitos, condutas, ideias e sentimentos em seu meio e horizonte. As diferentes construções diferem em qualidade e significado. Dentre os elementos mais importantes do espaço construído está o habitat do homem, o seu lar, carregado de valores existenciais e simbólicos (SCHUTZ, 1979; TUAN, 2013; DARDEL, 2011). O lugar é a síntese entre o homem e a Terra em sua subjetividade, valores e significados. Esta geograficidade representa, segundo Dardel (2011), "a natureza da realidade geográfica".

Apesar de sua multiplicidade, o lugar é singular. Como sujeitos, os seres humanos constroem lugares de pertencimento e identidade e são, ao mesmo tempo, moldados por tais lugares. Esta troca sujeito $\mathrm{x}$ objeto, entre os indivíduos e seus lugares (elementos inseparáveis), "constroem obstáculos à tendência pós-moderna e metropolitana de ver cada lugar como o resumo de todos os outros" (BERDOULAY E ENTRINKIN, 2012, p.112).

Por ser base da existência humana e centro de significação, postulação esta sugerida por Entrikin (1980), o lugar possui diversas dimensões (DARDEL, 2011). Nas reflexões de Bachelard (2008) o lugar carrega a essência da noção de casa, representando a topo(grafia) de nosso ser íntimo. Em outra corrente do pensamento, encontramos em Santos (2002) a seguinte formulação para o lugar: depositário obrigatório do evento e teatro insubstituível das paixões humanas. Neste contexto, torna-se base da reprodução da vida e produto das relações humanas de acordo com Carlos, 1996. Ao lado disso, o lugar nas palavras de Armando Corrêa da Silva ganha propriedade de dimensão espacial em sua inteireza e totalidade do que se poderia supor ser a realidade (SILVA, 1988). Segundo os cânones 
da humanística perspectiva, o espaço dotado de valor e significado emerge ao patamar de lugar ou lar (TUAN, 2013). Por meio da leitura de suas múltiplas definições, pode ser considerado um universo vivido, não apenas em sua concretude e objetividade, mas com todas as parcialidades da imaginação humana (BACHELARD, 2008).

Em sua multidimensionalidade, o lugar é um ente híbrido composto por materialidade, simbolismo, espacialidades, temporalidades e pela existencial maneira de vivenciá-lo. Conciliar e decodificar esta multiplicidade que representa a natureza da geografia (DARDEL, 2011) deve ser a tarefa desenvolvida pelos geógrafos que desejam uma abordagem que privilegie as diferentes dimensões do vivido.

\section{CONSIDERAÇÕES FINAIS}

Há tantas geografias quantas são as interpretações do mundo vivido de cada indivíduo e/ou grupos sociais (JOHNSTON, 1986 A). Partindo da ideia de que "o conhecimento do lugar é calcado na experiência" (HOLZER, 1992), os geógrafos humanísticos têm se debruçado sobre as experiências vividas, buscando nos relatos das pessoas comuns o alicerce com vista às suas investigações. Nesta vertente, o ser humano é o ator geográfico que, ao transformar o seu meio ambiente, modifica, igualmente, a sua vida de relações (JOHNSTON, 1986 B). Isso ocorre porque, na indissociabilidade fenomenológica que norteia o humanismo em geografia, o indivíduo não é distinto de seu lugar (RELPH, 1976). Sendo assim, quando o lugar passa por transformações de diversas ordens ou provocadas por dissabores, podem ocorrer mudanças existenciais. Nesses casos, é comum, igualmente, a mudança de relação das pessoas com seu mundo vivido (FERNANDES 2003; 2006; 2010).

Objetivando o rompimento com os paradigmas positivistas e neopositivistas, cujas abordagens privilegiavam apenas os aspectos palpáveis e quantificáveis da realidade, a fenomenologia, desde o início, impeliu os adeptos do humanismo em geografia a deslocar sua atenção dos sistemas espaciais para a experiência humana em seus significados, sejam eles negativos ou positivos (BUTTIMER, 1982; MELLO, 2005). O genuíno conhecimento do lugar, no entanto, envolve - tanto seus valores 
subjetivos: vivências afetivas, experiências íntimas, pertencimentos, decepções, simbolismos, significados, a vida de relações e a existencial maneira de viver de seus moradores - quanto suas características e valores objetivos: particularidades físicas, estrutura interna, dimensão dinâmica, atributos naturais, localização, valorização imobiliária, nível de urbanização etc. (LOWENTHAL, 1982; FERNANDES; 2009; 2012). Vale frisar que as citadas dimensões são inseparáveis, considerando-se a abordagem humanística em sua postura fenomenológica que privilegia a indissociabilidade sujeito/objeto.

Ao assumir que o conhecimento não existe independentemente do ser humano, a fenomenologia apregoa que o saber geográfico precisa ser obtido por meio da experiência humana do mundo. Nesse sentido, o método fenomenológico é oferecido ao geógrafo como um procedimento em suas abordagens sobre o lugar (RELPH, 1970). Em suas investigações, as experiências vividas são fundamentais para o descortinar da multidimensionalidade do lugar dotado de "traços físicos, atividades e funções observáveis e significados ou símbolos" ( HOLZER, 1992, P. 251).

Por serem visíveis, os fatos e fenômenos observáveis podem "servir de ponte entre os enfoques objetivo e subjetivo da geografia" (SACK, 1976). Em sua concepção clássica, o humanismo valoriza a existência em detrimento aos objetos e/ou mundo material (HOLZER, 1992). A principal preocupação da geografia humanística sempre esteve relacionada à vivência dos indivíduos em suas atividades cotidianas (BUTTIMER, 1982; MELLO, 2005). O vivido, no entanto, pressupõe o material e o nãomaterial; o concreto e o abstrato; o objetivo e o subjetivo; o lugar em sua morfologia e dinâmica espacial e os seus vivenciadores em seus significados e experiências (FRÉMONT, 1982). Como negligenciar a materialidade e os eventos espaciais que nos saltam aos olhos? Será que o mundo material que nos cerca, bem como as dinâmicas pelas quais estamos envoltos, não influenciam nossa existência?

\section{REFERÊNCIAS}


ABREU, Maurício de Almeida. A Apropriação do Território no Brasil Colonial. In: CASTRO, Iná Elias de; GOMES, Paulo César da Costa; CORRÊA, Roberto Lobato (Org). Explorações Geográficas: Percursos no Fim do Século. Rio de Janeiro: Bertrand Brasil, 1997. p.197-245.

Cidades: Espacialidades e Temporalidades. In: CARLOS, Ana Fani Alessandri ; LEMOS, Amália Inês Geraiges

(Orgs). Dilemas Urbanos: novas abordagens sobre a cidade. São Paulo: Contexto, 2003. 430 p.

ALMEIDA, Maria Geralda de. Os cantos e encantamentos de uma geografia sertaneja de Patativa do Assaré. In: MARANDOLA JR, Eduardo; GRATÃO, Lúcia Helena Batista (Orgs). Geografia e Literatura: ensaios sobre geograficidade, poética e imaginação. Londrina: Eduel, 2010. 354 p.

ANTONELLO, Ideni Terezinha. As territorialidades amazônicas reluzem na narrativa literária de Peregrino Júnior. In: MARANDOLA JR, Eduardo; GRATÃO, Lúcia Helena Batista (Orgs). Geografia e Literatura: ensaios sobre geograficidade, poética e imaginação. Londrina: Eduel, 2010. 354 p.

BACHELARD, Gaston. A poética do espaço. São Paulo: Martins Fontes, 2008. 242 p.

BASTOS, Ana Regina Vasconcelos Ribeiro. Espaço e Literatura: algumas reflexões teóricas. Revista Espaço e Cultura, Rio de Janeiro, n. 5, 1998.

BERDOULAY, Vicent; ENTRIKIN, John Nicholas. Lugar e Sujeito: perspectivas teóricas. In: MARANDOLA JR, Eduardo et al. Qual o espaço do lugar?: geografia, epistemologia, fenomenologia. São Paulo: Perspectiva, 2012.307 p.

BONNEMAISON, Joel. Viagem em Torno do Território. In: CORRÊA, Roberto Lobato; ROSENDAHL, Zeny (Org). Geografia Cultural: um Século (3). Rio de Janeiro: EdUERJ, 2002. p. 83-131.

BUTTIMER, Anne. Apreendendo o Dinamismo do Mundo Vivido. In: CHRISTOFOLETTI, Antônio (Org). Perspectivas da Geografia. São Paulo: DIFEL, 1982. p. 165-193.

CARLOS, Ana Fani Alessandri. o Lugar no/do Mundo. São Paulo: Hucitec, 1996.

CLAVAL, Paul. A Geografia Cultural. Florianópolis: Editora da UFSC, 2007. 453 p.

CORRÊAA, Roberto Lobato. O Espaço Urbano. 4.ed. São Paulo: Ática, 2000. 94 p.

A Geografia Cultural e o Urbano. In: CORREA, Roberto Lobato; ROSENDAHL, Zeny (Org). Introdução à geografia cultural. Rio de Janeiro: Bertrand Brasil, 2003. p. 167-186.

Sobre a geografia cultural. In: Textos NEPEC (volume 3). Rio de Janeiro: UERJ, 2007.

A espacialidade da cultura. In: CD cultura. Rio de Janeiro: UERJ, 2011.

CORRÊA, Roberto Lobato; ROSENDAHL, Zeny. Geografia Cultural: apresentando uma antologia. In: CORREA, Roberto Lobato; ROSENDAHL, Zeny (Orgs). Geografia Cultural: uma antologia (1). Rio de Janeiro: EdUERJ, 2012. 344 p.

COSGROVE, Denis. Em direção a uma geografia cultural radical: problemas da teoria. In: CORRÊA, Roberto Lobato;; ROSENDAHL, Zeny (Org). Introdução à geografia cultural. Rio de Janeiro: Bertrand Brasil, 2003. 224 p.

A Geografia Está em Toda Parte: Cultura e Simbolismo nas Paisagens Humanas. In: CORRÊA, Roberto Lobato; ROSEndAHL, Zeny (Org). Paisagem, Tempo e Cultura. Rio de Janeiro: EdUERJ, 2004. p. 92-123.

COSTA, Otávio. Memória e Paisagem: em busca do simbólico dos lugares. Espaço e Cultura, Rio de Janeiro, Ed.

Comemorativa 1993-2008, p. 149-156, 2008. 
DARDEL, Eric. O Homem e a Terra: natureza da realidade geográfica. São Paulo: Perspectiva, 2011. 159 p.

ENTRIKIN, John Nicholas. O Humanismo Contemporâneo em Geografia. Boletim de geografia teorética, São Paulo, v. 10, 1980.

FERNANDES, Marcio Luis. Ilha de Guaratiba: De Espaço a Lugar. 2003. 44 f. Trabalho de Conclusão de Curso (Graduação em Geografia) Centro Universitário Moacyr Sreder Bastos: Rio de Janeiro, 2003.

A Valorização do "Espaço" produzindo a valoração do "Lugar": 0 caso de Ilha de Guaratiba - R.J. 56 f. Monografia (Especialização em Geografia) - Universidade do Estado do Rio de Janeiro, Rio de Janeiro, 2006.

Por uma Necessária Mudança de Valores: uma proposta para a produção de um espaço (urbano) que privilegie o uso e não a troca. In; SIMPÓSIO NACIONAL O RURAL E O URBANO NO BRASIL, 2, 2009. Rio de Janeiro. Anais... Rio de Janeiro: UERJ, 2009. Não paginado.

Decodificando geografias pretéritas e hodiernas de Ilha de Guaratiba. (Dissertação de mestrado). Rio de Janeiro: PPGEO/UERJ, 2010. $99 \mathrm{f}$.

O Caráter Identitário da Toponímia. In: Congresso Internacional do Núcleo de Estudo das Américas, 3, 2012. Rio de Janeiro. Anais... Rio de Janeiro: UERJ, 2012. Não paginado.

Um outro horizonte em busca da humanização da geografia. Revista Geograficidade, Niterói, v. 4, n. 1, p. 78-87, Verão 2014.

FREITAS, Inês Aguiar de; PERES, Waldir Rugero; RAHY, Ione Salomão. A Janela de Hitler. GeoUERJ, Rio de Janeiro, n. 6, p. 29-36, 1999.

FRÉMONT, Armand. Histoire d'une Recherche. In: Frémont et ali. Espace Vécu et Civilisations. Paris: CNRS, 1982.106 p.

GALLAIS, Jean. Alguns Aspectos do Espaço Vivido nas Civilizações do Mundo Tropical. In: CORRÊA, Roberto Lobato; ROSENDAHL, Zeny (Org). Geografia Cultural: um século (3). Rio de Janeiro: EdUERJ, p. 63-81, 2002.

GEIGER, Pedro Pinchas. Contribuição ao debate sobre espacialidades e temporalidades urbanas. In: CARLOS, Ana Fani Alessandri; LEMOS, Amália Inês Geraiges (Orgs.). Dilemas Urbanos: novas abordagens sobre a cidade. São Paulo: Contexto, 2003. 430 p.

GEERTZ, Clifford. A interpretação das culturas. Rio de Janeiro: LTC, 2013. 213 p.

GOMES, Paulo César da Costa. Geografia e Modernidade. Rio de Janeiro: Bertrand Brasil, 2007. 366 p.

HAESBAERT, Rogério. Da desterritorialização à multiterritorialidade. In: encontro de geógrafos da América Latina EGAL, 10. São Paulo: USP, 2005.

HALL, Stuart. Representations: cultural representations and signifying practices. London: Routledge publications, 1997.

HARVEY, David. Condição Pós-moderna: uma pesquisa sobre as origens da mudança cultural. São Paulo: Edições Loyola, 1992. 349 p.

HOLZER, Werther. A geografia humanista: sua trajetória de 1950 a 1990 (Dissertação de mestrado). Rio de Janeiro: PPGEO/UFRJ, 1992. $550 \mathrm{f}$. 
HOLZER, Werther. A Geografia Humanista: uma revisão. Espaço e Cultura, Rio de Janeiro, Ed. Comemorativa 19932008, p. 137-147, 2008.

JOHNSTON, Ronald John. Introducion el estúdio internacional de la historia de la geografia. In: JOHNSTON, Ronald

John; CLAVAL, Paul (Orgs). La geografia Actual: geógrafos y tendências. Barcelona: Ariel, 1986 A. p. 13-25.

Geografia e Geógrafos: a geografia humana anglo-americana desde 1945. São Paulo: Difel, 1986 B. 359 p.

LOWENTHAL, David. Geografia, experiência e Imaginação: Em direção a uma epistemologia geográfica. In:

CHRITOFOlETTI, Antônio. Perspectivas da Geografia. São Paulo: DIFEL, 1982. p. 103-141.

MARANDOLA JR, Eduardo. Sobre Ontologias. In: MARANDOLA JR, Eduardo et al. Qual o espaço do lugar?: geografia, epistemologia, fenomenologia. São Paulo: Perspectiva, 2012. 307 p.

MASSEY, Doren. Pelo Espaço: Uma Nova Política da Espacialidade. Rio de Janeiro. Bertrand Brasil, 2008.312 p.

MELLO, João Baptista Ferreira de. Geografia Humanística: A Perspectiva da Experiência Vivida e Uma Crítica Radical ao Positivismo. Revista Brasileira de Geografia, Rio de Janeiro, p. 91-115, 1990.

Dos Espaços da Escuridão aos Lugares de Extrema Luminosidade: O Universo da Estrela Marlene como e documento para a construção de conceitos geográficos. 2000. Tese (Doutorado em Geografia) - Universidade Federal do Rio de Janeiro, Rio de Janeiro, 2000.

Descortinando e (Re)pensando Categorias Espaciais com Base na Obra de Yi-Fu Tuan. In: CORREAA, Roberto

Lobato; ROSENDAHL, Zeny (Org). Matrizes da geografia cultural. Rio de Janeiro: EdUERJ, 2001. p. 87-101.

Símbolos dos Lugares, dos Espaços e dos "Deslugares”. Espaço e Cultura. Rio de Janeiro, v. 16, p. 64-72, 2003.

Valores em Geografia e o Dinamismo do Mundo Vivido na Obra de Anne Buttimer. Espaço e Cultura, Rio de Janeiro, v. 19-20, p. 33-40, 2005.

OLIVEIRA, Lívia de. 0 sentido de lugar. In: MARANDOLA JR, Eduardo et al. Qual o espaço do lugar?: geografia, epistemologia, fenomenologia. São Paulo: Perspectiva, 2012. 307 p.

PANOFSKY, Erwin. Significado das artes visuais. São Paulo: Perspectiva, 2004.

RELPH, Edward. An inquiry into the relations between phenomenology and geography. Canadian Geographer, v. 14, n. 3, p. 193-201, 1970.

Place and Placelessness. London: Pion, 1976. 156 p.

Reflexões sobre a emergência, aspectos e essências de lugar. In: MARANDOLA JR, Eduardo et al. Qual o espaço do lugar?: geografia, epistemologia, fenomenologia. São Paulo: Perspectiva, 2012. 307 p.

SACK, Robert David. Magic and space. Annals ot the association of American geographers, v. 66, n. 2, p. 309-322, 1976.

SALGUEIRO, Teresa Barata. Espacialidades e temporalidades urbanas. In: CARLOS, Ana Fani Alessandri ; LEMOS, Amália Inês Geraiges (Orgs). Dilemas Urbanos: novas abordagens sobre a cidade. São Paulo: Contexto, 2003.430 p.

SANTOS, Milton. A Natureza do Espaço: Técnica e Tempo, Razão e Emoção. São Paulo: EDUSP, 2002. 384 p.

SCHUTZ, Alfred. Fenomenologia e relações sociais. Rio de Janeiro: Zahar, 1979. 319 p. 
SILVA, Armando Corrêa da. O espaço fora do lugar. São Paulo: Hucitec, 1988. 128 p.

SOUZA, Marcelo Lopes de. ABC do Desenvolvimento Urbano. 2.ed. Rio de Janeiro: Bertrand Brasil, 2005.190 p

TUAN, Yu Fu. Espaço, Tempo e Lugar: Um Arcabouço Humanista. Revista Geograficidade, Niterói, v. 1, n. 1, p. 8-19, Inverno 2011.

Topofilia: Um Estudo da Percepção, Atitudes e Valores do Meio Ambiente. Londrina: Eduel, 2012. 344 p.

Espaço e Lugar: A Perspectiva da Experiência: Londrina. Eduel, 2013. 248 p.

WRIGHT, John. Terrae incognitae: the place of the imagination in geography. Annals of the Association of American Geographers, v. 37, p. 01-15, 1947. 